\title{
Stress and burnout among doctors
}

\author{
Rabindran ${ }^{1}$, Gedam DS \\ ${ }^{1}$ Dr. Rabindran, Consultant Neonatologist, Billroth Hospital, Chennai, Tamilnadu, India, ${ }^{2}$ Dr D Sharad Gedam, Professor \\ of Pediatrics, L N Medical College, Bhopal, India.
}

Address for Correspondence: Dr Rabindran, E mail: rabindranindia@yahoo.co.in

\begin{abstract}
Occupational stress is increasingly faced by doctors. Upto some extent, stress improves performance but when excessive, it becomes harmful. Doctors have more stress related mental health problems than general population. Burnout is inability to cope with emotional stress at work. It consists of 3 domains; emotional exhaustion, depersonalization \& lack of personal accomplishment. Various models like demand-control imbalance, effort-reward imbalance \& support model explain evolution of work related stress. Common causes of stress are related to patient care, decision making, taking responsibility, increasing use of technology, continuing rises in health care costs, turbulence within work environment, long working hours \& over-working. Stress causes physical symptoms, mental derangements, emotional \& behavioural disturbances. Research suggests that high stress levels may impair immune system with increased risk of cardiovascular disease \& cancer. Stress can be modified by appropriate stress management skills like avoiding cynicism, reading, joining a support group, attending a wellness conference, strengthening communication skills, addressing to spiritual needs, meditation \& decreasing caffeine. Burnout prevention should be done both on both personal \& organizational levels. Appropriate interventions like improving inter-professional relationships, changes in work environment, modifying off duty time \& streamlining decision making should be done to mitigate the effect of stress on doctors.
\end{abstract}

Keywords: Stress, Burnout, Stress management.

\section{Introduction}

Occupational stress is now being increasingly faced by health care workers [1]. Stress has a physiological association with illness. It is a relationship between person \& environment that is appraised by the person as taxing the resources \& endangering wellbeing [2]. It is a process which precipitates individuals to believe they are unable to cope with the situation facing them. However something which may be overtaxing to one person may be exhilarating to another, hence personality traits influence the stress equation [3]. Upto some extent, stress improves performance \& quality of life, but when excessive, it becomes harmful. Prevalence of stress related mental health problems in physicians are higher than in general population [4]. A study among UK hospital specialists showed that between $22-46 \%$ exhibited significant psychiatric morbidity [5]. Most sensitive to stress are doctors working in emergency departments \& at intensive care units (ICU) [6], where routine work

Manuscript Received: $14^{\text {th }}$ November 2015

Reviewed: $25^{\text {th }}$ November 2015

Author Corrected: $15^{\text {th }}$ December 2015

Accepted for Publication: $30^{\text {th }}$ December 2015 demands highly technical environment \& specialized doctors [7].

Physiology of Stress reaction: Stress reaction results from outpouring of adrenaline into blood stream resulting in a fight-or-flight response. Changes during this response include tachycardia, raised blood pressure, tachynea, tensing of muscles, increased mental alertness, increased sensitivity of sense organs, redistribution of blood flow to brain, heart \& muscles. There is an increase in blood sugar, fat, cholesterol \& a rise in platelets \& clotting factors [8].

Burnout: Burnout syndrome was identified in early 1970s [9] among human service professionals, mostly healthcare workers [10]. It is common among physicians with rates ranging from 25-60\% [11], depending on the working conditions \&medical specialty [12]. Burnout is an inability to cope with emotional stress at work [13] or as excessive use of energy / resources leading to feelings of failure \& exhaustion [14]. Maslach Burnout Inventory described 


\section{Review Article}

burnout as an erosion of the soul caused by a deterioration of one's values, dignity, spirit \& will. It is a prolonged response to chronic emotional \& interpersonal job related stressors. It consists of 3 domains: 1) emotional exhaustion-emotionally drained, depleted \& worn out by work \& not able to recover in non-working hours; 2) depersonalization-development of a negative, callous \& cynical attitude toward patients; 3) lack of personal accomplishment- tendency to see work negatively \& feeling incompetent [11]. It is a state in which individuals expect little reward \& considerable punishment from work because of a lack of valued reinforcement, controllable outcomes or personal competence [15]. It lowers work performance [16], reduces quality of patient care [17], increases sickness absence [18] \& motivates idea to leave the profession [19].Though physicians recognize symptoms of mental disorder, they don't seek professional help \& deny existence of problems because asking for help could be interpreted as professional weakness \& working disability [20].

Models explaining stress: Various models like demand-control imbalance [21], effort-reward imbalance [22] \& support model [23] explain the evolution of work related stress. Demand-control imbalance model states that jobs are stressful when combined with high demands with no authority to alter the situation; perceived low control is the major source of work stress \& predicts poor physical \& mental health outcomes [24]. Demands may be insufficient time, conflicting demands, high expectations \& emotional intensity of the work; \& Controls may be decision latitude (sufficient authority to make decisions) \& skill discretion (sufficient training to give a sense of mastery). Hence stress results from simultaneous high demand \& low control. According to effort-reward imbalance model, stress results from lack of reciprocity between effort \& reward. Efforts include demands (extrinsic) \& coping (intrinsic); Rewards include work satisfaction, remuneration, recognition, esteem \& status [22]. According to support model, stress results from inadequate physical \& social support [23]. Support includes instrumental support in the form of physical environment \& effective infrastructure; relational support like agreeable, supportive colleagues \& appreciative superiors.

Causes of stress: Common causes of stress are related to patient care, decision making, taking responsibility [25], increasing use of technology, continuing rises in health care costs, turbulence within work environment
[26], long working hours \& over-working [27]. Most stressful situations are explaining relatives about a dying patient \& witnessing their reaction [28]. Medicolegal threat, hostile \& emotionally difficult patients, violence, negative media representation, interference with family life \& lack of appreciation are sources of subjective stress for doctors [29]. Compassion fatigue - stress that comes from caring too much can strike any healthcare worker [30]. Males show higher level of stress compared to female as males are expected to shoulder more responsibility during work compared to women. Junior staff have higher level of stress than seniors. Singles have higher stress levels compared to married [31] because singles are exposed to more work compared to married \& divorced. Those with lowest salary show higher level of stress scores because they don't earn enough money to cover their basic needs. Doctors working in afternoon shifts have higher level of stress because afternoon staffs are less experienced $\&$ hence more liable to stress with the possibility of more activities taking place during afternoon [31]. Shift rotation \& working nights are more stressful [32]. Role overload, role ambiguity \& role conflict are also significant stressors [33].

Effects of stress: Stress causes physical symptoms, mental derangements, emotional \& behavioural disturbances. Physical symptoms include fatigue, headache, insomnia, muscle stiffness, palpitation, chest pain, abdominal cramps, nausea, trembling, flushing \& sweating. Mental derangements include decrease in concentration \& memory, indecisiveness, mind racing/ going blank, confusion \& loss of sense of humor. Emotional disturbances associated with stress are anxiety, nervousness, depression, anger, frustration, worry, fear, irritability, impatience, short temper [5], impaired quality of life, depressive reactions \& even suicides [34]. Behavioral disturbances include pacing, fidgeting, nail-biting, foot-tapping, eating more [35], smoking, drinking [18], drug abuse [36], crying, yelling, swearing, blaming, hitting \& even throwing objects. Symptoms of burnout include emotional exhaustion, depression, low sense of professional accomplishment, depersonalization \& poor mental health [18]. Research suggests that high stress levels may impair immune system with increased risk of cardiovascular disease \& cancer.

Stress management: Stress can be modified by appropriate stress management skills. Some techniques include avoiding cynicism, reading, joining a support group, attending a wellness conference, strengthening 


\section{Review Article}

communication skills, addressing to spiritual needs, meditation \& decreasing caffeine. Simply focusing attention on one's own breathing gives relaxation. Progressive relaxation \& massage helps releasing tension in muscles. Regular aerobic exercise, Visualization and guided imagery like daydreaming/ fantasizing moderates effect of stress on emotions \& promotes relaxation.

Spearmint, chamomile tea \& passionflower are good in providing relaxation. When expectations are realistic, life feels more predictable \& manageable. Reframing is a technique of changing the way of looking at things in order to feel better about them which relieves stress.

Burnout prevention \& treatment: Burnout prevention should be done both on both personal \& organizational levels. Personal measures include self awareness, mindfulness training, appreciative inquiry, narrative medicine, work life balance, maintaining healthy boundary between work $\&$ non-work life areas, learning effective leadership skills, exerting control over work hours \& focussing on meaningful work activities. Organizational preventive measures include regular monitoring for physician burnout, educational programs teaching personal burnout prevention, funding physician support meetings, providing leadership skills training \& supporting flexible work hours.

\section{Conclusion}

Stress \& burnout are major mental health problems among physicians today which have a negative impact on health \&work quality. Appropriate interventions like improving inter-professional relationships, changes in work environment, modifying off duty time\& streamlining decision making should be done to mitigate the effect of stress on doctors.

Conflict of interest: None declared.

Funding: Nil, Permission from IRB: Yes

\section{References}

1. Burbeck R, Coomber S, Robinson SM, Todd C. Occupational stress in consultants in accident and emergency medicine: A national survey of levels of stress at work. Emerg Med J 2002;19:234-238 doi:10.1136/emj.19.3.234.

2. Michie S. Causes and management of stress at work. Occup Environ Med 2002;59:67-72 doi:10. 1136 /oem.59.1.67
3. French JR, Caplan RD. Organizational stress and individual strain. In: Marrow AJ, editor. The failure of success. New York: AMACOM; 1972. pp. $30-66$.

4. Tyssen R: Health problems and the use of health services among physicians: a review article with particular emphasis on Norwegian studies. Ind Health 2007; 45:599- 610.

5. Kapur N, Borrill C, Stride C. Psychological morbidity and job satisfaction in hospital consultants and junior house officers: multicentre, cross sectional survey. BMJ 1998;317:511-12.

6. Baig A, Siddiqui I, Naqvi H, Sabir S, Jabbar J, Shahid M. Correlation of serum cortisol levels stress among medical doctors working in emergency departments. J Coll Physicians Surg Pak. 2006 Sep; 16(9):576-80

7. Coomber S, Todd C, Park G, et al. Stress in UK intensive care unit doctors. Br. J. Anaesth. (2002) 89 (6): 873-881.doi: 10.1093/bja/aef273

8. Le Pidou, Maria; Kadda, Olga; Argyriou, Georgios; Nestor, Athanasia; Marvaki, Katerina; Hanioti, Georgia; Nanas, Serafeim .Ethical Dilemmas as a Source of Stress among Doctors and Nurses in the Intensive Care Unit. Nosileftiki . Apr-Jun 2012, Vol. 51 Issue 2, p187194. $8 \mathrm{p}$

9. Goldberg R, Boss RW, Chan L, et al. Burnout and its correlates in emergency physicians: four years' experience with a wellness booth. Acad Emerg Med. 1996 Dec;3(12):1156-64.

10. Maslach C, Schaufeli WB, Leiter MP. Job burnout. Annu Rev Psychol. 2001;52:397-422.

11. Grassi L, Magnani K. Psychiatric morbidity and burnout in the medical profession: an Italian study of general practitioners and hospital physicians. PsychotherPsychosom 2000;69:329-334 ; DOI:10. 1159/000012416.

12. Ramirez AJ, GrahamJ, Richards MA, etal.Mental health of hospital consultants: the effects of stress and satisfaction at work. Lancet. 1996 Mar 16; 347(9003):724-8.

13. Pines A, Maslach C. Characteristics of staff burnout in mental health settings. Hosp Community Psychiatry $1978 ; 29: 233-237$. 


\section{Review Article}

14. Freudenberger H. The staff burn-out syndrome in alternative institutions. Psychotherapy: Theory, Research and Practice 1975; 12:73-83.

15. Meier ST. Towards a theory of burnout. Hum Relat 1983; 36: 899-910. doi: 10.1177/001872678303601003

16. Shanafelt TD, Balch CM, Bechamps G, Russell T, Dyrbye L, Satele D et al.: Burnout and medical errors among American surgeons. Ann Surg. 2010 Jun;251(6):995-1000. doi: 10.1097/SLA. 0b013e3 181 bfdab3.

17. Firth-Cozens J: Interventions to improve physicians' wellbeing and patient care. SocSci Med2001;52:215-22.

18. Michie S \& Williams S: Reducing work related psychological ill health and sickness absence: a systematic literature review. Occup Environ Med 2003; 60:3-9. doi: 10.1136/oem.60.1.3

19. Chong A, Killeen O, Clarke T. Work -Related Stress among Paediatric Non Consultant Hospital Doctors.Ir Med J. 2004; 97:203-205

20. Stanton J, Randal P. Doctors accessing mentalhealth services: an exploratory study. BMJ Open 2011;1:e000017. doi:10.1136/bmjopen-2010-000017

21. Karasek RA. Job demands, job decision latitude and mental strain: implications for job redesign. Admin Sci Q. 1979;24:285-307.

22. Siegrist J. Adverse health effects of high-effort/lowreward conditions. J Occup Health Psychol. 1996 Jan;1(1):27-41.

23. Johnson JV, Hall EM. Job strain, work place social support, and cardiovascular disease: a cross-sectional study of a random sample of the Swedish working population. Am J Public Health. 1988 October; 78(10): 1336-1342.

24. Bosma H, Stansfeld SA, Marmot MG. Job control, personal characteristics, and heart disease. J Occup Health Psychol. 1998 Oct;3(4):402-409.

25. Menzies IE. Nurses under stress. Internal Nurs Rev 1960;7:9-16.
26. Blair Á, Littlewood Ì. Sources of stress. J Community Nurs 1995;40:38-9.

27. Mansour A, Riad W, Moussa A. The occupational fatigue in anesthesiologists: illusion or real? Middle East J Anaesthesiol. 2010 Feb;20(4):529-34.

28. Malgorzata Grzeskowiaka, Alicja BartkowskaSniatkowskab, Jowita Rosada-Kurasinskab, Iwona Kielbasiewicz- Drozdowskac, Piotr K. Janickid. Jobrelated stress in PICU .Stress assessment by anaesthesiologists and nurses working in paediatric intensive care units; Eastern Journal of Medicine 17 (2012) 59-66.

29. Schattner P, Coming. The stress of metropolitan general practice.Med J Aust 1998; 169: 133-137.

30. Geoffrey J Riley. On being a doctor. Understanding the stresses and strains of being a doctor . Med J Aust 2004; 181 (7): 350-353.

31. Hussein J, Aniza I, Ahmad Taufik J. Factors associated with organizational stress among intensive care unit healthcare workers, in Somalia Hospital. Malaysian Journal of Public Health Medicine. 2012;12(1):57-66.

32. Lewis DJ, Robinson JA. ICU nurses coping measures: response to work-related Stressors. Critical Care Nurse 1992; 12(2): 18-25.

33. Leatt P, Schneck R. Perceptions of stress by nurses in different specialities: some implications for nursing administrators. Nursing Papers 1983; 15: 19-32.

34. Schernhammer ES \& Colditz GA: Suicide rates among physicians: a quantitative and gender assessment (metaanalysis). Am J Psychiatry 2004; 161:2295-302.

35. Hope A, Kelleher CC, O’Connor M. Lifestyle practices and the health promoting environment of hospital nurses. Journal of Advanced Nursing 1998; 28: 438-447.

36. Firth-Cozens J: Individual and organizational predictors of depression in general practitioners. $\mathrm{Br} \mathrm{J}$ Gen Pract 1998, 48:1647-1651.

\section{How to cite this article?}

Rabindran, Gedam DS. Stress and burnout among doctors. Int J surg Orthopedics 2015;1(2):28-31. doi: 10.17511/ijoso.2015.i2.02. 